\title{
COVID-19: May hospitals in one province of South Africa reserve empty beds for patients from their province and turn down emergency requests from other provinces?
}

\author{
D J McQuoid-Mason, BComm, LLB, LLM, PhD \\ Centre for Socio-Legal Studies, University of KwaZulu-Natal, Durban, South Africa
}

Corresponding author: D J McQuoid-Mason (mcquoidm@ukzn.ac.za)

\begin{abstract}
The new 501Y.V2 variant of COVID-19 has led to a rapid increase in the number of persons infected with the virus in South Africa, and state and private hospitals are having to turn patients away. Although it is common practice for patients to be transferred between provinces for specialist care, the upsurge in the COVID-19 pandemic has led to some hospitals considering reserving intensive care and critical care beds for COVID-19 patients from their province. The Constitution provides that nobody may be refused emergency medical treatment, nor may they be unfairly discriminated against. This is also implicit in the 'equitable' provision of healthcare services referred to in the National Health Act 61 of 2003. The Critical Care Society of Southern Africa COVID-19 guidelines, or other similar widely accepted guidelines, may be used, provided they do not unfairly discriminate against patients on the basis of age. According to the Constitution, a hospital that wishes to turn away an emergency treatment request from another province because it is reserving beds for COVID-19 patients from its home province will have to show that it is 'reasonable and justifiable' to do so. It will have to show that the other province's patient was being subjected to the same criteria for admission as its home province COVID-19 patients, because, for instance, occupation of the bed by another COVID-19 patient from the home province was imminent.
\end{abstract}

S Afr Med J 2021;111(4):304-306. https://doi.org/10.7196/SAMJ.2021.v111i4.15554

The question has arisen, particularly in the private sector, whether a hospital in one province of South Africa (SA) may reserve COVID19-designated intensive care unit (ICU) empty beds for patients from their province, and turn down emergency COVID-19 requests from other provinces. Some hospitals situated in provinces that have become COVID-19 'hotspots' are considering reserving beds for patients from their provinces in anticipation of a rapid increase in the number of COVID-19 patients requiring oxygen and ventilation. In order to answer this question, it is necessary to consider: (i) the steep rise in the number of COVID-19 cases and the shortage of oxygen and ICU COVID-19-designated hospital beds; (ii) the provisions of the Constitution, ${ }^{[1]}$ the National Health Act No. 61 of $2003^{[2]}$ and the Disaster Management Act No. 57 of 2002; ${ }^{[3]}$ level 3 COVID-19 regulations; ${ }^{[4]}$ (iii) the Critical Care Society of Southern Africa (CCSSA) COVID-19 guidelines; ${ }^{[5]}$ and finally, in the light of the above considerations, (iv) whether a hospital in one province may reserve COVID-19-designated ICU empty beds for patients from their province, and may turn down emergency COVID-19 requests from other provinces.

\section{The steep rise in the number of COVID-19 cases and shortage of oxygen and ICU COVID-19 hospital beds}

The new 501Y.V2 variant of COVID-19 has proved to be transmitted much more quickly than the original SARS-CoV-2 virus. ${ }^{[6]}$ During the December 2020 festive season, some private hospitals in KwaZuluNatal and Western Cape provinces began to run out of oxygen and beds for COVID-19 patients, and concern was expressed that the same would happen in Gauteng. ${ }^{[7]}$ During this period, the number of COVID-19 cases increased by $>100000$ in only 9 days. ${ }^{[7]}$ On 30 December, there was a spike in infections, with $>17000$ positive infections reported within 24 hours. ${ }^{[8]}$ The country's three largest private hospital groups reported that the surge in COVID-19 cases had filled some of their ICUs to capacity, and some of the hospitals were diverting ambulances to other facilities. ${ }^{[6]}$ The SA 501Y.V2 variant has led to a rapid increase in new cases and deaths in excess of what the country experienced during the first surge of COVID-19 in late July 2020. ${ }^{[9]}$ Before the COVID-19 pandemic, it was common practice to transfer patients requiring special or emergency care to hospitals in other provinces that had the capacity to deal with them. ${ }^{[10]}$ In principle, there is no reason why the same should not be done for COVID-19 patients - as is implicit in the equality clauses in the Constitution, ${ }^{[1]}$ the National Health Act $^{[2]}$ and the exceptions provided in the Disaster Management Act COVID-19 regulations. ${ }^{[3]}$

\section{The relevant provisions of the} Constitution, the National Health Act and the Disaster Management Act regullations

The Constitution ${ }^{[1]}$ provides that everyone has the right of access to healthcare, within available resources, and nobody may be refused emergency medical treatment (s27). It also provides that children have a right to healthcare (s28). Furthermore, everyone is entitled to equality, which means that they are entitled to 'the full enjoyment of all rights and freedoms' (s9). Nobody may be unfairly discriminated against on a number of listed grounds, including age. A listed ground means that unfairness will be presumed on the part of the 
discriminating party (s9), where a person in the listed category has been discriminated against. People may also not be discriminated against on other unlisted grounds, but in such cases the onus is on the person alleging discrimination to prove unfairness. Therefore, no prospective ICU or critical care patients may be excluded on the grounds of age, ${ }^{[11]}$ or of residing in another province.

All these rights, however, may be limited if it is reasonable and justifiable to do so and the least restrictive means is used (s36). For instance, the Constitutional Court has held that it is reasonable and justifiable, when there is a shortage of resources, to provide kidney dialysis only to patients who are good candidates for a kidney transplant. It was therefore lawful to deny kidney transplants to persons who are suffering from incurable comorbidities such as chronic kidney failure, which makes them unsuitable candidates for kidney transplants. ${ }^{[12]}$ The Constitutional Court has also held that a 'significant segment of society' may not have their rights limited, because the Constitution requires that limitations must be of 'general application. ${ }^{[13]}$ It has therefore been suggested that COVID-19 patients requiring access to available ventilators for extended periods in order to survive can be regarded as requiring emergency medical treatment, and may not be denied access simply because they have COVID-19. This is because although their condition may be chronic, it is not incurable. They must be excluded for the same reasons as other patients with comorbidities. ${ }^{[14]}$

The healthcare provisions in the Constitution ${ }^{[1]}$ are echoed in the National Health Act. ${ }^{[2]}$ The objects of the Act are to establish a national health system that 'encompasses public and private providers of public health services' (s2(a)), and to provide healthcare services 'in an equitable manner to the population of the Republic, with the best possible health services that available resources can afford' (s2). The objects also include to protect, respect, promote and fulfil the rights of 'the people of South Africa to the progressive realisation of the constitutional right of access to health care services', and to provide children with 'basic health care services' (s2). The Act further imposed a duty on the Minister of Health 'within available resources' to 'equitably prioritise the health services that the State can provide' (s3). A similar duty is imposed on the National Department of Health, provincial departments of health and municipalities (s3). The reference to 'equitable' means that access to healthcare must be 'fair, just or reasonable. ${ }^{[15]}$ COVID-19 patients from one province requiring emergency medical treatment may therefore not be unfairly, unjustly or unreasonably excluded from healthcare establishments in another province, if they would have qualified for admission as residents in the latter, and resources are available.

The Disaster Management Act COVID-19 regulations ${ }^{[4]}$ provide for controlled visits by members of the public to health establishments and facilities, including the prohibition against visiting hospitals 'except to receive treatment or medication' (regulation 41). There is not currently a ban on interprovincial travel, so the level 3 COVID19 restriction $s^{[5]}$ would not prevent patients who need specialist or emergency care from being transferred to healthcare facilities in other provinces.

\section{The CCSSA guidelines during the COVID-19 public health emergency}

The CCSSA has issued guidelines on the Allocation of scarce critical care resources during the COVID-19 public health emergency in South Africa' that are aimed at providing guidance for critically ill patients where such an emergency 'creates demand for critical resources (e.g. ventilators, critical care beds) that outstrips the supply! ${ }^{[5]}$ The guidelines stress that the triage system should be applied to all patients presenting with critical illnesses who meet the usual indications for ICU beds, not merely those with the disease or disorder that have caused the public health emergency'. ${ }^{[5]}$ The requirement that the application of the triage system must be to 'all patients who meet the usual indications for ICU beds' is consistent with the provisions of the Constitution, ${ }^{[1]}$ which state that where rights are limited the limitation has to be 'of general application' (s36), and not aimed at a segment of society. ${ }^{[13]}$ Patients infected with COVID-19 who require ICU or critical care beds should therefore be triaged like any other patients requiring ICU beds.

The CCSSA guidelines use a combination of the Sequential Organ Failure Assessment (SOFA) and Clinical Frailty Scale scores to calculate points for patients, to determine their priority for admission to ICUs or critical care facilities. ${ }^{[5]}$ Patients are grouped into three colour-coded priority groups $(\mathrm{red}=$ high priority, orange $=$ medium priority, and yellow = low priority). Where there is a scarcity of critical care facilities, the red group gets priority over the orange and yellow groups. If the red group have all been accommodated, the orange group gets priority over the yellow group. If both the red and orange groups have been accommodated, the yellow group is admitted to the critical care facility. ${ }^{[5]}$ According to the guidelines, patients who are refused critical care must still be offered palliative care, and this is consistent with the Health Professions Council of South Africa Guidelines for the Withholding and Withdrawing of Treatment. ${ }^{[16]}$

The CCSSA COVID-19 guidelines mention that, where there is a tie between patients within the same priority groups, 'Life-cycle considerations with priority going to younger patients' should be considered. ${ }^{[5]}$ In response to criticisms of some of the provisions of the CCSSA COVID-19 guidelines, ${ }^{[17]}$ the CCSSA Council has sought to clarify the position by stating that 'age should never be used as a solitary exclusion criterion for ICU care. ${ }^{\text {[18] }}$ However, immediately prior to this statement, the Council mentioned that although the British Medical Association 'stresses that younger patients should not be automatically prioritised over older ones, ${ }^{[19]}$ they emphasise that 'the age issue is a point of British law and not a position driven primarily by ethics. ${ }^{\text {[17] }}$ The CCSSA COVID-19 guidelines appeared to have overlooked the fact that in terms of the Constitution, ${ }^{[1]}$ patients may not be unfairly discriminated against on grounds such as age (s9). ${ }^{[11]}$ When admitting patients who have tied within the same priority groups, the deciding factor should not be age, but rather the prognosis for a good recovery, based on comorbidities or other factors applicable during triage to all prospective ICU or critical care patients.

\section{May a hospital in one province reserve} COVID-19-designated ICU empty beds for patients from their province, and turin down emergency COVID-19 requests from other provinces?

As a general rule, in terms of the Constitution ${ }^{[1]}$ hospitals may not refuse to provide emergency medical treatment (s27). Therefore, if a 'walk-in' patient from another province requires emergency medical treatment in an ICU bed, and such a bed is available - provided the patient's condition is not chronic and incurable ${ }^{[12]}-$ the patient must be provided with such a bed. ${ }^{[14]}$ The CCSSA COVID-19 guidelines $^{[5]}$ (without the age restrictions), or a similar generally accepted protocol ${ }^{[16]}$ for admission to ICU or critical care facilities, may be used for COVID-19 patients requiring an available COVID19 earmarked ICU bed - provided such guidelines do not unfairly discriminate against COVID-19 patients (e.g. on the grounds of age $^{[11]}$ or because they are from another province).

The same principle applies to a hospital with an empty bed, when a patient is delivered by a road or air ambulance from another 
province. However, before transferring a patient, the emergency response service 'advanced life support' team ${ }^{[10]}$ or the senior clinician on duty in casualty at the relevant transferring hospital in the first province should determine, in consultation with the relevant clinician working in critical care in the prospective receiving hospital, whether such a patient would qualify for admission to an ICU or critical care facility in the latter. In the case of COVID-19 patients, when using the CCSSA COVID-19 guidelines (without age restrictions), ${ }^{[1]}$ or similar generally accepted guidelines, ${ }^{[16]}$ care must be taken to ensure that there is no unfair discrimination against patients seeking to be transferred.

Likewise, when a clinician in a hospital in one province contacts the relevant clinician working in critical care in a hospital in another province that has an empty COVID-19-designated ICU bed, the same criteria apply. It is lawful to differentiate hospital wards and beds for different medical conditions - provided there is a legitimate purpose and rational basis for the differentiation of eligible patients for admission to the dedicated wards or beds, and all are treated equally without discrimination. ${ }^{[20]}$ This is because in terms of the Constitution ${ }^{[1]}$ any limitation on access to healthcare must be of 'general application' to all patients in the same differentiated category (s36). There is no doubt that COVID-19 is a highly infectious airborne pathogen, and it serves a rational, legitimate purpose to earmark certain ICU wards for COVID-19 patients only - provided that the admission criteria used to admit them are not discriminatory.

If the prospective receiving hospital wishes to hold an empty designated COVID-19 bed because there has been an exponential rise in the number of COVID-19 cases in the province, the hospital will have to show that the refusal to accommodate the patient from another province was 'reasonable and justifiable' in terms of the Constitution (s36). This will only be possible if, for example, the hospital can show that occupation of the empty bed by a COVID-19 patient from their own province is imminent, and that it treats all its emergency COVID19 patients - irrespective of where they are from - in the same manner. The latter can be shown by using objective criteria such as the CCSSA COVID-19 guidelines ${ }^{[5]}$ (without the age restrictions ${ }^{[11]}$ ), or some other non-discriminatory generally accepted guidelines, ${ }^{[15]}$ for allocating COVID-19-designated ICU or critical care beds.

\section{Conclusions}

In the light of the above, the following conclusions can be drawn:

- The new 501Y.V2 variant of COVID-19 has led to a rapid increase in the number of persons infected with the virus, and some hospitals in the public and private sectors becoming overwhelmed and having to turn patients away.

- The transferring of patients requiring special healthcare from a hospital in one province to a hospital in another province is common practice in both the public and private spheres - where the receiving hospital is not short of the designated beds.

- The Constitution provides that everyone has the right of access to healthcare, no one may be refused emergency medical treatment, and no one may be unfairly discriminated against.

- All rights in the Constitution may be limited provided the limitation is of general application, is reasonable and justifiable, and is the least restrictive means of attaining its objective.

- The National Health Act also emphasises the importance of an equitable and fair approach regarding access to healthcare.

- The CCSSA COVID 19 guidelines provide an algorithm for calculating whether patients should be eligible for ICU or critical care treatments. However, such an algorithm must not be discriminatory (e.g. on the basis of age, or because a patient is from another province), and must be applied equally to all COVID-19 patients, irrespective of where they are from.

- Where the receiving hospital wishes to hold an empty designated COVID-19 bed, because there has been a sharp increase in the number of COVID-19 cases in the province, the hospital will have to show that the refusal to accommodate a patient from another province was 'reasonable and justifiable', because the other province's patients were being subjected to the same criteria for admission as the home province COVID-19 patients (for instance, occupation of the bed by another COVID-19 patient from their province was imminent).

\section{Declaration. None.}

Acknowledgements. None.

Author contributions. Sole author.

Funding. National Research Foundation.

Conflicts of interest. None.

1. South Africa. Constitution of the Republic of South Africa, No. 108 of 1996. http://justice.gov.za/ legislation/constitution/SAConstitution-web-eng.pdf (accessed 13 January 2021).

2. South Africa. National Health Act 61 of 2003. www.gov.za/documents/national-health-act (accessed 13 January 2021)

3. South Africa. Disaster Management Act 57 of 2002. www.gov.za/documents/disaster-management-act (accessed 13 January 2021).

4. South Africa. Disaster Management Act: Regulations: Alert level 3 during Coronavirus COVID-19 lockdown. https://www.gov.za/covid-19/about/alert-level-3-during-coronavirus-covid-19-lockdown (accessed 14 January 2021).

5. Critical Care Society of Southern Africa. Allocation of scarce critical care resources during the COVID-19 public health emergency in South Africa. 2 April 2020. https://criticalcare.org.za/wp-content uploads/2020/04/Allocation-of-Scarce-Critical-Care-Resources-During-the-COVID-19-Public-HealthEmergency-in-South-Africa.pdf (accessed 14 January 2021).

6. World Health Organization. SARS-CoV-2 variants. 31 December 2010. https://www.who.int/csr/don/31World Health Organization. SARS-CoV-2 variants. 31 December 2010.
december-2020-sars-cov2-variants/en/ (accessed 13 January 2021).

7. Daniel L. Hospital update: Some ICUs now full, with Netcare 'extremely concerned' about Gauteng Daniel L. Hospital update: Some ICUs now full, with Netcare 'extremely concerned' about Gauteng.
Business Insider SA, 28 December 2020. https://www.news24.com/news24/southafrica/news/kzn-healthBusiness Insider SA, 28 December 2020. https://www.news24.com/news24/southafrica/news//zzn-health-
care-system-crippled-as-paramedics-battle-covid-19-overflow-20201227 (accessed 13 January 2021).

care-system-crippled-as-paramedics-battle-covid-19-overflow-20201227 (accessed 13 January 2021).
8. Naidoo Y, Singh O. Staff and oxygen shortages in second wave tremor, front-line workers fear Covid-19 tsunami. TimesLIVE, 3 January 2021. https://www.timeslive.co.za/news/south-africa/2021-0103-staff-and-oxygen-shortages-in-second-wave-tremor-front-line-workers-fear-covid-19-tsunami/ (accessed 13 January 2021).

9. Kozlov M. South African SARS-CoV-2 variant alarms scientists. The Scientist, 5 January 2021. https://www.the-scientist.com/news-opinion/south-african-sars-cov-2-variant-alarms-scientists-68317 (accessed 13 January 2021).

10. Cf. Muhlbaue D, Naidoo R, Hardcastle TC. An analysis of patients transported by a private helicopter emergency medical service in South Africa. S Afr Med J 2016;106(2):201-205. https://doi:org/10.7196 SAMJ.2016.v106i2.9919

11. Cf. The Free Library. Age discrimination in critical care triage in South Africa: The law and the allocation of scarce health resources in the COVID-19 pandemic. 2020. https://www.thefreelibrary.com/ allocation of scarce health resources in the COVID-19 pandemic. 2020. https: $/ /$ www.thefreelibrary.com/
Age+discrimination+in+critical+care+triage+in+South+Africa\%3a+The+law...-a0643541244 (accessed Age+discrimination

12. Soobramoney v Minister of Health (KwaZulu-Natal) 1998 (1) SA 765 CC).

12. Soobramoney v Minister of Health (KwaZulu-Natal) 1998 (1) SA 765 CC).
13. Government of the Republic of South Africa v Grootboom 2001 (1) SA 46 (CC).

14. McQuoid-Mason DJ. Do COVID-19 patients needing extended care in an intensive care unit fall under the 'emergency medical treatment' provisions of the Constitution? S Afr Med J 2021;111(1):23-25. https:// doi.org/10.7196/SAMJ.2021.v111i1.1524

15. Hornby AS. Oxford Advanced Dictionary of Current English. 3rd ed. Oxford: Oxford University Press, 1974:289.

16. Health Professions Council of South Africa. Guidelines for the Withholding and Withdrawing of Treatment. Pretoria: HPCSA, 2008. https://www.hpcsa.co.za/Uploads/Professional_Practice/Ethics Booklet.pdf (accessed 14 January 2021).

17. Singh JA, Moodley K. Critical care triaging in the shadow of COVID-19: Ethics considerations. S Afr Med J 2020;110(5):355-359. https://doi.org/10.7196/SAMJ.2021.v110i5.14778

18. Gopalan PD, Joubert IA, Paruk F, et al.; Critical Care Society of Southern Africa Council. The Critical Care Society of Southern Africa guidelines on the allocation of scarce critical care resources during
Gopalan Care Society of Southern Africa guidelines on the allocation of scarce critical care resources during
the COVID-19 public health emergency in South Africa. S Afr Med J 2020;110(8):700-703. https://doi.

19. British Medical Association. COVID-19

9. British Medical Association. COVID-19 - ethical issues: A guidance note. https://www.bma.org.uk/

media/2226/bma-covid-19-ethics-guidance.pdf (accessed 16 January 2021).
20. Currie I, de Waal J. The Bill of Rights Handbook. 6th ed. Cape Town: Juta \& Co. Ltd, 2015:219. 